\title{
SMART Pressure Regulation In Main Oil Pipeline
}

\author{
Dmitry P. Starikov, Evgeny A. Rybakov, Evgeny I. Gromakov \\ Institute of Cybernetics \\ National Research Tomsk Polytechnic University \\ Tomsk, Russian Federation \\ dstarikov@me.com
}

\begin{abstract}
Regulation with help of simultaneous using of pump and valve in applying to main oil pipeline pressure control is researched in the article. An energy efficient mode for this system is being calculated. Article describes an algorithm and an idea of economic pressure stabilization.
\end{abstract}

Keywords-Pressure control; valve; automatic control; pump; frequency controlling.

\section{INTRODUCTION}

Main pipeline pumps are difficult technical constructions and play crucial part in oil pipeline transportation.

Parts of them are intended for oil supply form buster pumps to main pipeline. And others are used for energy losses replenishment during pressure control and also for pipeline hydrodynamic separation on given in draft sectors to provide pumping and hydra impact effects localization in main pipeline. The main problem of oil transportation is pressure maintenance set by regulatory requirements. The recent time tendency of pressure regulation is controlling pressure by pump rotating speed changing.

To provide desired operating mode main pump stations include serially connected pumps, which are controlled with frequency adjustable motors with high power consuming.

This power depends on an oil supply volume in pipeline $Q$ and value of pressure $H$ :

$$
P_{p}=\frac{Q H g \rho}{\eta_{p} \eta_{e l} \eta_{f c}},
$$

where $g$ and $\rho$ - acceleration of gravity and oil density;

$\eta_{p}, \eta_{e l}, \eta_{\mathrm{fc}}$ - efficiency of a pump, power suppliers, frequency converter.

And can reach up to megawatt of consuming.

The main aim of this work is automatic pressure control system (APCS) increasing which can decrease main pump energy consumption in dynamic and stabilization mode.

Stationary or trigger modes are being considered in comparative calculations of energy consuming in frequency adjustable main pumps. But it is not counted that pump is in a control loop and therefore the actuator of this loop will consume power to overcome internal resistance caused by huge weight of motor shaft.

During bad quality regulation (oscillations and overshooting) that losses may be significant. This fact follows from pump motion equation:

$$
n_{c} \frac{G D^{2}}{375} \frac{d \omega}{d t}=M_{p}-M_{s} \text {, }
$$

where $G D^{2}$ - the turning moment of the pump; $M_{p}=\frac{3 I^{2} R^{2}}{s}-$ moment of a pump motor; $n_{s}$ - synchronous speed of rotating;

$I$ - loop current;

$R$ - loop active resistance;

$s$ - slipping;

$M_{S}$ - moment of resistance on motor shaft.

Internal losses caused by continuous pump accelerations and decelerations are proportional to motor acceleration during transient and motor moment and engine rotor. The last one is significant for huge pumps.

At the same time energy losses in dynamic mode in valve are less than in pump. This fact is caused by lower lag of valves during moving from point.

That is why simultaneous use of frequency controlled pump and throttling component is an attractive solution of pressure control problem. In this way it is possible to implement power economic consumption system.

For decreasing of internal moment value it is needed to provide smooth frequency changing of pump power and fast regulation of valve motor. But eigenfrequency of fast loop must be higher than pump loop.

And in this case valve loop can suppress high frequency influences of ACS dynamic and release pump loop from that influence regulation. But pump loop should suppress low frequency parts of dynamic. And in steady and quasi-steady modes the opening degree of a valve should be maximum.

In real pressure control system lag of pump and valve differ by an order. Big currents supplying provide relatively small pump acceleration time. The special system of smooth frequency changing is used for excluding hydra impacts during acceleration. At the same time it is impractical to use that system during pressure stabilization in main oil pipeline. Generally valve lag is around 100 
seconds. And this value of eigenfrequency must be changed appropriately.

Adding low frequency filter in pump loop and choosing quite fast valve moving may solve this problem. Filter is an aperiodic link, which can be written as:

$$
W_{f}(s)=\frac{k_{f}}{T_{f}+1}
$$

where $k_{f}$ - direct transfer coefficient;

$$
T_{f} \text { - time constant (lag). }
$$

If big value of a pump filter lag will be chosen it will be possible to provide (by an algorithm) smooth speed changing of a pump. This way the necessity of big currents using for switching pump mode will disappear and as a result unnecessary power losses will be excluded.

The typical scheme of a system Pump Station Pipeline is shown on Figure 1.

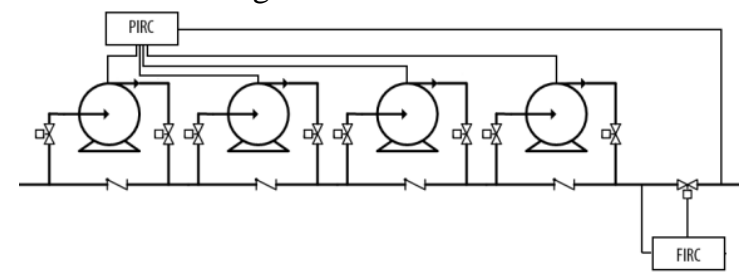

Figure 1. Typical oil transport scheme

Fig. 1 shows that the scheme involves the presence of at least two loops ACS (including possible variations). Will continue to be considered a combination of control algorithms: Split range control and parallel control.

The main goal is to choose an algorithm (scheme) under control optimality criterion relative to a functional energy intensity (the choice of the type of control depending on the amount of energy used).

\section{MODELLING}

Research model valve and pump was developed in MatLAB Simulink. Block diagram of the valve is shown in fig. 2.

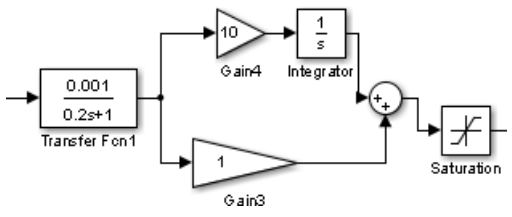

Figure 2. Valve model

In this model, factors Gain4 and Gain3 are coefficients of a PI controller [17] of valve position. Also, the control input latches integrated high-pass filter. Constraint is caused by the physical limits of the valve and the presence of stroke. In Fig. 3 pump model is presented.

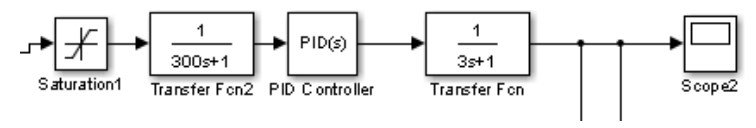

Figure 3. Pump model

Willfully missing saturation pump output is used to add clarity to the proposed algorithm. There is a low pass filter, which in conjunction with the pump makes it fast to the slower unit to conserve power (and more smoothly varying the operating point of the pump). Block diagram of the pipeline is shown in Fig. 4.

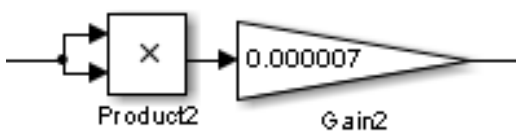

Figure 4. Pipeline model

The proposed algorithm for controlling the pressure of the structure is presented in Fig. 5.

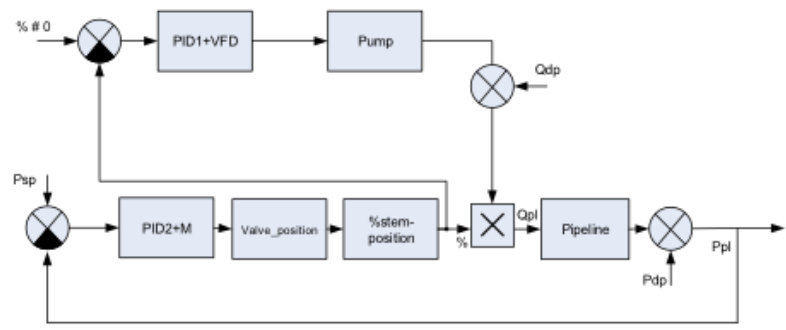

Figure 5. Automatic pressure control system structure

Suppose that in the initial state, the valve is fully open (opening degree $\%_{\mathrm{OD}} \sim 0,9$ ) and the operating point of the pump corresponds to the set level of oil supply $\left(\mathrm{P}_{\mathrm{SP}}\right)$.

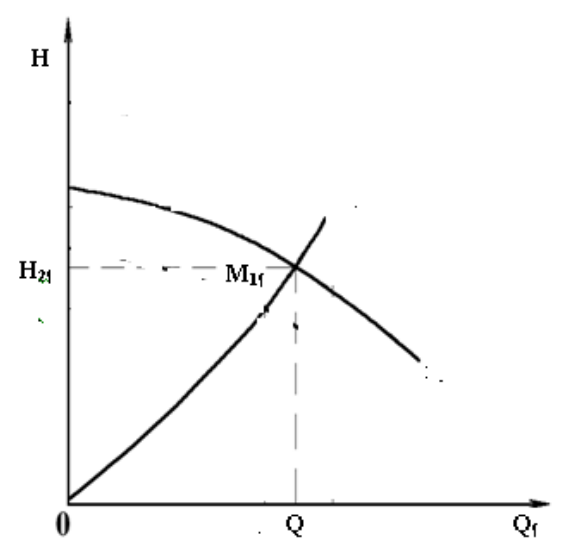

Figure 6. Operating point diagram

\section{RESEARCH}

Fig.7 represents a model of a set of the system in Simulink. The pump, valve and systems dependencies are 
important for exploring and for clarity in general. These charts are shown on Fig. 8 - Fig. 10.

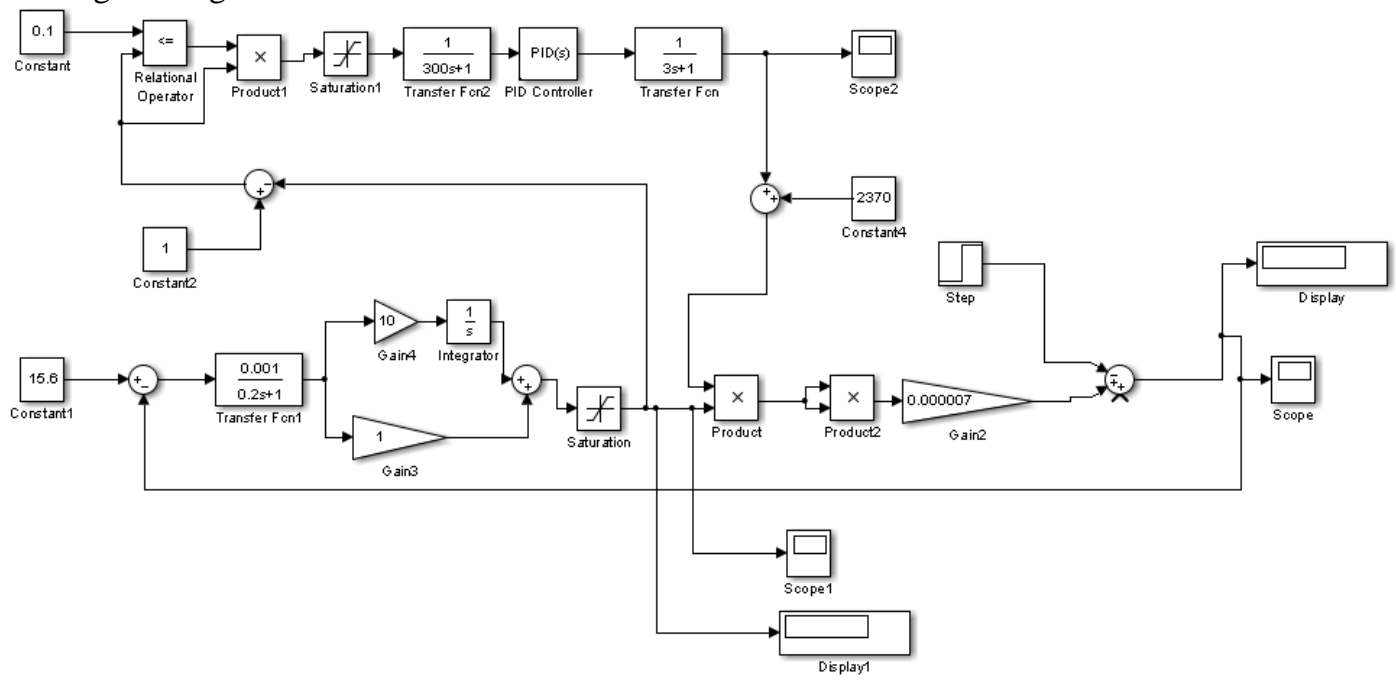

Figure 7. Simulink model

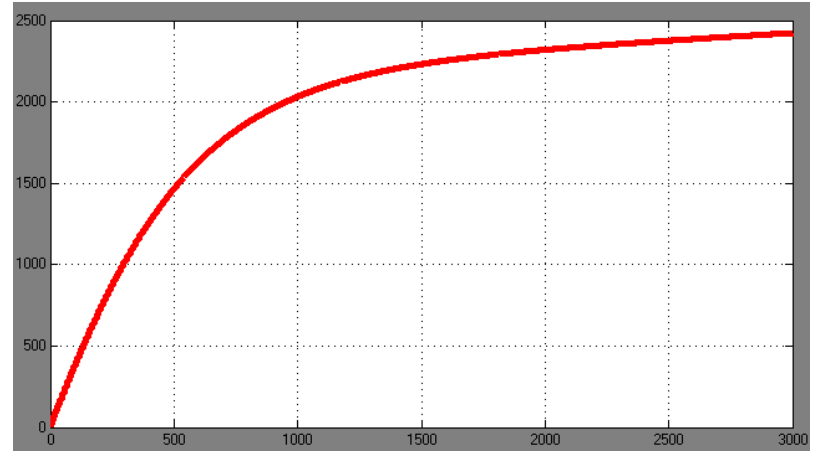

Figure 8. Pump trend

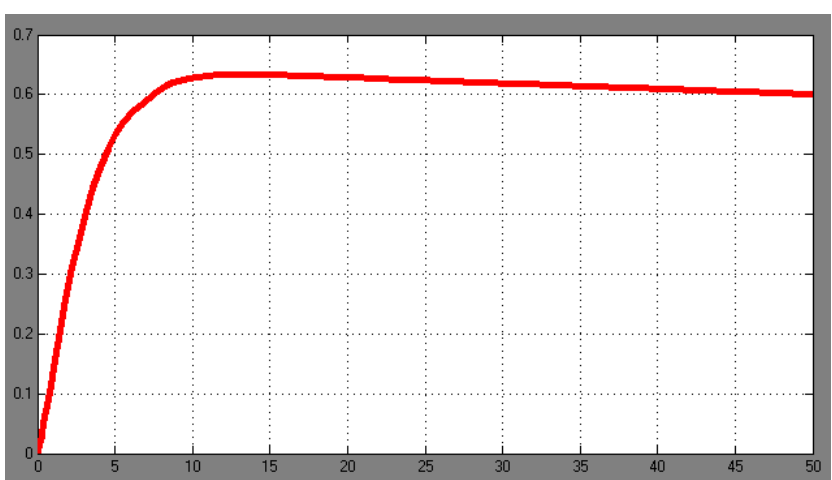

Figure 9. Valve trend

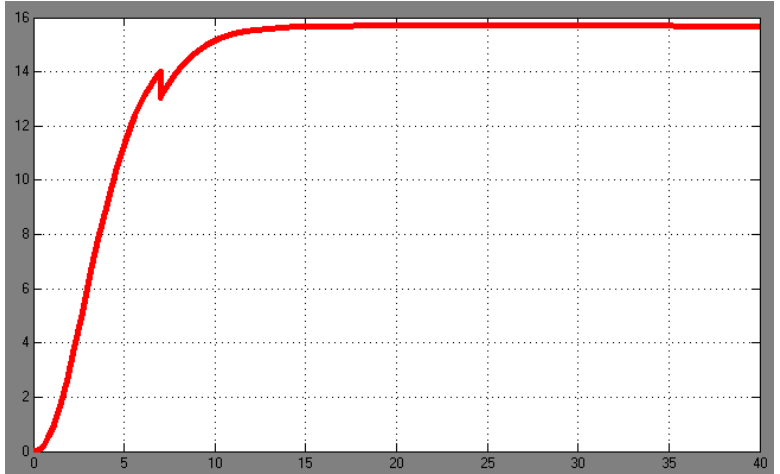

Figure 10. Pressure trend

Research was conducted in a simulated pressure drop in the pipeline of the order of $6 \mathrm{kPa}$. When such a perturbation the system is stable.

\section{CONCLUSION}

According to simulation, obtained data can be concluded about the prospects and feasibility of the proposed two-loop circuit automatic control system pressure. During the research was performed that a variety of parametric reconfiguration, which indicate the ease of configuration automatic control system, pressure in transient operating without oscillation and overshoot. The inertia torque component of the actuator shaft can be readily reduced by pulling the smooth acceleration when outputting pumpoperating mode to a new operating point of the pressure oil supply. 


\section{REFERENCES}

[1] Starikov D.P., Rybakov E.A., Gromakov E.A. Minimization of pump energy losses in dynamic automatic control of pressure in the main oil pipeline// FCICS-2014, Beijing, 2014

[2] B. Roffel, B.H.L. Betlem, "Advanced Practical Process Control" Springer, 2004.

[3] Carlos A. Smith, Principles and Practice of Automatic Process Control 2nd edition John Wiley \& Sons, Inc..2006, 563 p.

[4] Charles L. Phillips, John M. Parr Feedback Control Systems. 5th edition Prentice Hall PTR, 2011, 774 p

[5] Harnefors L. H-P- Nee "Model-Based Current Control of AC Machines Using the Internal Control Model Method" IEEE Transactions on Industry Applications, Vol 34, No 1, January/ February 1998, pp 133-141

[6] Jean Pierre Corriou, "Process Control: Theory and applications" Springer, 2004.

[7] Ma Z and Wang S, Energy efficient control of variable speed pumps in complex building central air-conditioning systems", Energy and Buildings, Vol.41, 2009, pp.197-205.

[8] Pedersen G.K. and Yang. Z.,Efficiency Optimization of a Multi-pump Booster system. Proc. of Genetic and Evolutionary Computation Conference (GECCO-2008), Atlanta, Georgia, USA, Jul 12-16 2008, pp.1611-1618.

[9] Perez M. A., Cortes P., and Rodriguez J., Predictive control algorithm technique for multilevel asymmetric cascaded hbridge inverters, IEEE Transactions on Industrial Electronics, vol. 55, no. 12, pp. 4354-4361, Dec. 2008.

[10] Reeves D, Study on improving the energy efficiency of pumps, European Commission, 2001.

[11] Shiels S, Optimizing centrifugal pump operation", World Pumps, Jan.2001, pp.35-39.

[12] Thomas O. Miesner, William L. Leffler Oil \& Gas Pipelines in Nontechnical Language PennWell Corp, 2006, 357 p.
[13] Yang Z. and H. Borsting., Energy Efficient Control of a Boosting System with Multiple Variable-Speed Pumps in Parallel, 49th IEEE Conference on Decision and Control Atlanta, Georgia USA, December 15-17, 2010, pp.2198-2203.

[14] Zhongwen Wang, Ruizhen Duan and Xiaoqiu Xu, Model Identification of Hydrostatic Center Frame Control System based on MATLAB, Journal of Networks, Vol. No. 6, pp. 1322-1328, June 2013

[15] Popov D.N., Sosnovskii N.G. Strukturnyi metod modelirovaniia na EVM nestatsionarnykh protsessov $v$ sistemakh s lopastnymi nasosami [Structural method of computer simulations of nonstationary processes in systems with vane pumps]. Nauchno-tekhnich. konferentsiia 4-go Mezhdunarodnogo foruma PCVEXPO'2005 «Nasosy. Effektivnost' $i$ ekologiia.»: tez. dokl. [Scientific-technical conference of the 4-th International forum PCVEXPO'2005 «Pumps. Efficiency and ecology»: theses of reports], Moscow, 2005, pp. 13-14.

[16] Popov D.N. Osobennosti dinamiki upravliaemykh sistem s nasosami [Features of dynamics of controllable systems with pumps]. Mezhdunar. nauchno-tekhnich. konferentsiia «ECOPUMP.RU 2007. Effektivnost' $i$ ekologichnost' nasosnogo oborudovaniia»: tez. dokl. [International scientific-technical conference «ECOPUMP.RU 2007. Effectiveness and ecological properties of pump equipment»: theses of reports], Moscow, Bauman MSTU Publ., 2007, pp. 37-38.

[17] Kluev A.S., Lebedev A.T., Kluev S.A., Tovarov A.G. Naladka sredstv avtomatizacii I avtomaticheskih system upravleniya. Moscow.: Energoatomizdat, 1989, 368 p.

[18] Arshenevsky N.N., Pospelov B.B. Perehodnye process v krupnih nasosnih stanciyah. Moscow.: Energia, 1980, 112 p.

[19] Popov D.N., Sosnovsky N.G. Avtomaticheskoe regulirovanie davleniya na vhode $\mathrm{v}$ magistralnii nasos pri vikluchenii elektoprivoda. //ENTI Nauka I obrazovanie, 2013 